\title{
Road Tests of a Two-Wheeled Vehicle with the Use of Various Urban Road Infrastructure Solutions
}

\author{
Natalia Szymlet ${ }^{1 *}$, Piotr Lijewski', Beata Kurc² \\ 1 Faculty of Civil and Transport Engineering, Poznan University of Technology, pl. Marii Skłodowskiej-Curie 5 \\ 60-965 Poznań, Poland \\ 2 Faculty of Chemical Technology, Poznan University of Technology, pl. Marii Skłodowskiej-Curie 5 60-965 \\ Poznań, Poland \\ * Corresponding author's e-mail: natalia.r.szymlet@doctorate.put.poznan.pl
}

\begin{abstract}
Road traffic is a common phenomenon in cities, and all urban road users suffer its negative effects. Therefore, the subject of this article is a comparative analysis of the exhaust emissions of toxic compounds and the operating parameters of two-wheeled vehicles measured under real operating conditions. The comparison applies to two drive cycles: in the first, the vehicle was travelling in standard city traffic (without using the bus lanes), while in the second, the vehicle travelled on bus lanes, whenever those were available. Such analysis made it possible to evaluate the ecological usefulness of bus lanes by assessing the exhaust emissions and the travel time of the test vehicle. For this purpose, an analysis of the exhaust emission values in time was performed for gaseous compounds (HC, $\mathrm{CO}, \mathrm{CO}_{2}, \mathrm{NO}_{\mathrm{x}}$ ) from a scooter equipped with a $125 \mathrm{~cm}^{3}$ displacement engine with a maximum power of $9 \mathrm{~kW}$. The tests were carried out under real operating conditions in the city of Poznan. The route has been chosen so that it consisted of roads with a number of bus lanes. AXIONR/S+ mobile apparatus belonging to the PEMS (Portable Emissions Measurement Systems) group was used in the research. The device is one of the most modern measuring instruments, where the entire device is a suitcase weighing only $18 \mathrm{~kg}$ containing two analyzers for measuring the concentrations of both gaseous and solid exhaust components.
\end{abstract}

Keywords: air pollution, two-wheeled vehicles, exhaust emission, RDE methodology, bus lanes.

\section{INTRODUCTION}

According to the transport policy in the European Union, including Poland, the elimination of road congestion and greenhouse gas emissions, which are closely correlated, is an extremely important issue. The issue of reducing the urban congestion also fits into the idea of sustainable development, which is widely known, as evidenced by numerous studies on it $[\mathrm{a}, \mathrm{b}]$. The document issued on March 28, 2011 as the White Paper "Plan for the creation of a single European transport area - striving to achieve a competitive and resource-efficient transport system" is the basic record that characterises a coherent and sustainable transport policy for the EU member states [European Comission 2011]. This document has the status of a report, containing a proposal on a specific problem as issued by the European Commission and is not a legal act to which the EU countries are obliged. According to the provisions of the Book, the most important task of transport policy is "Ensuring the growth of the transport sector and supporting mobility while achieving the goal of reducing emissions by 60\%" [European Comission 2011]. This plan should be understood as a continuous increase in the share of transport services in the economy while taking care of the natural environment and reducing the harmful compounds generated by the sector in question.

The transport congestion is defined as the state of interaction of users, infrastructure and vehicles in which the unit costs of transport increase, which was discussed in [Ciesielski 1986]. These costs are associated with time, economic and environmental 
losses. The urbanisation rate in Poland currently reaches $61 \%$, while in the Wielkopolska voivodeship, this value is $54.27 \%$ (as of 2017). This is due to the existence of numerous road users (pedestrians, drivers, consumers of public transport), as well as many intersections, which leads to conflicts between them and transport congestion as a result. This problem applies not only to urban centers, but also to smaller cities, which are made up of significant transit routes.

According to the research, which is the subject of the dissertation [Igliński 2009], the level of Poznań congestion equal to 2.36 (defined as the indicator of the average increase in driving time) is much higher than in any city in the United States (2007) [Winston and Shirley 2004]. The main dissertation also identified the main causes of road congestion for the Poznań agglomeration, $80 \%$ was insufficient road capacity. The remaining $20 \%$ was caused by such factors as: low dynamics of truck traffic, failures and collisions, bad weather conditions and traffic light failures.

An effective strategy to reduce the urban congestion is the use of bus lanes, which are used to improve the urban transport. However, the rights to use them are regulated by the provisions of individual City Road Authorities. According to the standardization of the ZDM in Poznań, taxi services, municipal services, electric vehicles and, what is particularly important, in the aspect of this article, motorcycles and mopeds [ztm.poznan.pl 2020] can travel on bus lanes marked as "DOP". There are over $10 \mathrm{ki}-$ lometers of bus lanes in Poznań, which is only $2 \%$ in relation to the total length of the bus communication network. The reference of this value to the total length of urban roads in the agglomeration referred to as motorcycles and mopeds gives $0.97 \%$. Despite this state of affairs, the described solution was used in the strategic areas of the city of Poznań, which significantly reduced the road congestion and travel time, along with the economic and ecological losses, mainly for the public transport passengers and the twowheeled vehicle users.

With respect to mopeds and motorbikes, which are the subject of this study, the most interesting of all losses (time, economic and ecological) is the issue of environmental impact. One of the main causes of environmental pollution is the combustion of fuels from motor vehicles. Therefore, an extremely important aspect is the constant search for the solutions that reduce the negative impact of transport on the environment [Strzemkowski et al. 2019]. This applies to the issues related to their design, operation and indirectly also with the methods of measuring the exhaust emissions. It is this last aspect that has been intensively developed in the recent years, because it shows the scale of the problem and allows determining the most appropriate course of action. Many studies have shown [Bajerlein et al. 2014, Kaminska et al. 2019, Lijewski et al. 2019] that the largest share of vehicle operation time ( including two-wheeled vehicles) is idle standstill. This is due to the characteristics of the urban driving conditions (heavy traffic, numerous stops, traffic lights), which are components of road congestion. This translates directly into increased greenhouse gas emissions.

The problem raised in the article is a comparative analysis of the exhaust emissions of toxic gases and operating parameters of twowheel vehicle engines under real operating conditions. The comparison applies to two drive cycles: the first - the vehicle user was travelling in standard city traffic (without preference), while in the second - the user used bus lanes. Such analysis makes it possible to evaluate the ecological usefulness of bus lanes by assessing the emission of toxic compounds and the travel time of the test vehicle.

\section{METHODLOGY}

The test object, which is the subject of research on the impact of bus lanes on travel time and the toxic exhaust emissions, was a twowheeled urban vehicle. The scooter was equipped with a four-stroke engine, with a displacement of $125 \mathrm{~cm}^{3}$ and a maximum power of $9 \mathrm{~kW}$. The vehicle was manufactured in 2017, so it received type approval in accordance with the EURO 4 exhaust emission norm. Moreover, the manufacturer equipped the vehicle with a start-stop system and a three-way catalytic converter. The vehicle was inspected for possible technical defects before the emission tests began.

The tests were carried out under real operating conditions in the city of Poznań. The route has been chosen so that it consisted of roads with designated bus lanes (Fig. 1). For this reason, the measurements were taken in the western part of the city on ul. Bukowska (Fig. 2a). A bus lane extending from the intersection with ul. Bułgarska 


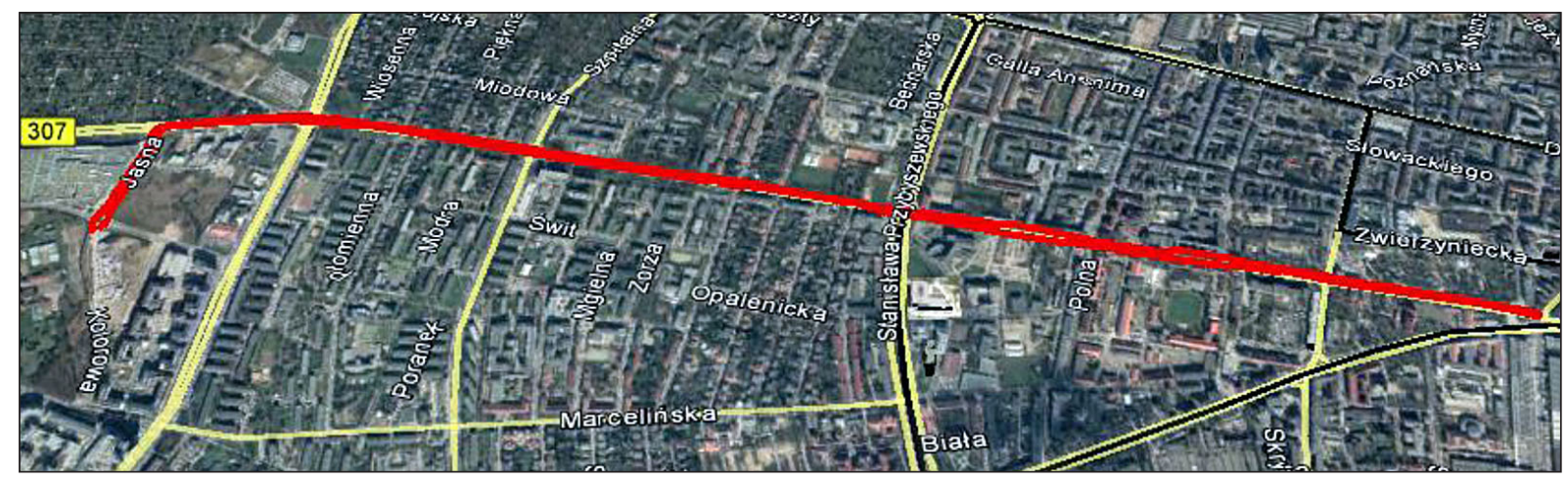

Figure 1. The test route visualisation [www.gpsvisualizer.com]

a)

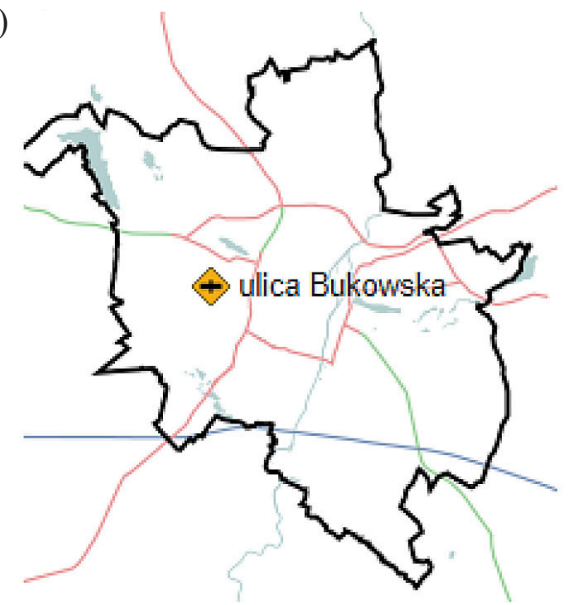

b)

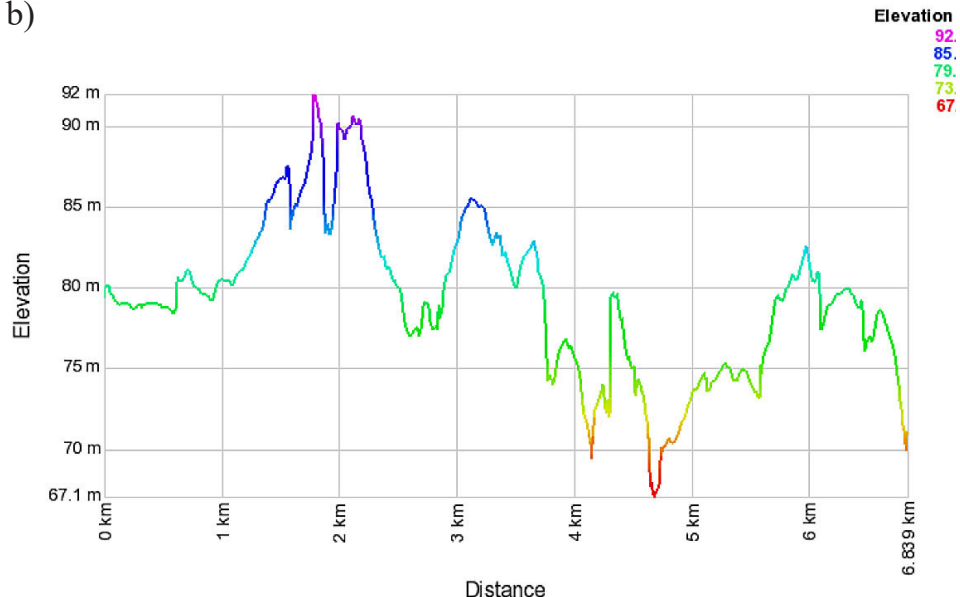

Figure 2. a) test route location, b) driving profile

and ul. Polska marked out towards the city center to ul. Przybyszewskiego, was used. The proximity of the airport and the route being the main connecting route between the western part of the city with the city centre generates significant road congestion on this section. In addition, the street connects the neighbouring municipalities, i.e. Tarnowo Podgórne or Dopiewo, with the city center of Poznań. The measurements were carried out in the afternoon, i.e. during the peak traffic hours characterised by heavy traffic, consisting mainly of passenger cars. The total length of the route was $6.6 \mathrm{~km}$, of which about $50 \%$ had a designated bus lane. The view of the route profile determined on the basis of the GPS device is shown in Figure $2 b$.

The AxionR/S+ equipment was used to measure the toxic exhaust emissions and the operating parameters necessary for the comparative analysis of two drive cycles. The device, like SEMTECH DS, used in many scientific works of the Institute of Internal Combustion Engines and Transport [Rymaniak, Ziokowski and Gallas 2017, Kaminska et al. 2019, Rymaniak et al.
2020], belongs to the PEMS (Portable Emissions Measurement System) group. These devices are used to measure the emission of toxic compounds and the engine operating parameters under real operating conditions. The difference is that the AxionR/S+ apparatus allows tests to be carried out on smaller vehicles, i.e. motorcycles and mopeds, which is owing to the features of the measuring device (small dimensions, low weight). The device measures the toxic gaseous compounds concentration: $\mathrm{CO}, \mathrm{CO}_{2}, \mathrm{NO}_{\mathrm{x}}, \mathrm{HC}$ as well as PM mass. The NDIR (Nondispersive Infrared Sensor) non-dispersive infrared analyzer was used to determine the emission of carbon-containing gaseous compounds, while the electrochemical analyzer was used to determine the $\mathrm{NO}_{\mathrm{x}}$ emission. In the case of particulate measurement, a method based on Laser Scatter was used. Table 1 presents the basic technical data of the AxionR/S+ measuring system.

Moreover, the manufacturer has equipped the device with a meteorological recording module, a GPS module and a module for recording the data from the on-board diagnostic system - OBD. 
Table 1. Technical specifications of the measuring apparatus [www.globarlmrv.com 2020]

\begin{tabular}{|c|c|c|c|c|}
\hline Gas & Mesaurement Range & Accuracy & Resolution & Type of Mesaurement \\
\hline $\mathrm{HC}$ & $0-4000 \mathrm{ppm}$ & $\pm 8 \mathrm{ppm}$ abs. or $\pm 3 \%$ rel. & $1 \mathrm{ppm}$ & NDIR \\
\hline $\mathrm{CO}$ & $0-10 \%$ & $\pm 0.02 \%$ abs. or $\pm 3 \%$ rel. & $0.001 \mathrm{vol} . \%$ & NDIR \\
\hline $\mathrm{CO}_{2}$ & $0-16 \%$ & $\pm 0.3 \%$ abs. or $\pm 4 \%$ rel. & $0.01 \mathrm{vol} . \%$ & NDIR \\
\hline $\mathrm{NO}$ & $0-4000 \mathrm{ppm}$ & $\pm 25 \mathrm{ppm}$ abs. or $\pm 3 \%$ rel. & $1 \mathrm{ppm}$ & E-chem \\
\hline $\mathrm{O}_{2}$ & $0-25 \%$ & $\pm 0.1 \% \mathrm{ppm}$ abs. or $\pm 3 \%$ rel. & $0.01 \mathrm{vol} . \%$ & E-chem \\
\hline $\mathrm{PM}$ & $0 \mathrm{mg} / \mathrm{m}^{3}$ to $300 \mathrm{mg} / \mathrm{m}^{3}$ & $\pm 2 \%$ & $0.01 \mathrm{mg} / \mathrm{m}^{3}$ & Laser Scatter \\
\hline
\end{tabular}

In the case of the vehicles not equipped with an OBD system, as it is for most two-wheeled vehicles, in order to determine the engine speed and load, the measuring system measures the pressure in the engine intake manifold and counts the number of electrical impulses of the spark plug wire (Fig. 3a). The apparatus measures and acquires data at a frequency of $1 \mathrm{~Hz}$. Figure $2 \mathrm{a}$ presents the test vehicle together with the AxionR/S+ research apparatus.

\section{RESULTS AND ANALYSIS}

\section{Operating parameters analysis}

The tests carried out under real operating conditions made it possible to plot the comparative travel time characteristics. This characteristic is a graphic representation of the share of the engine or vehicle operating time in specific ranges of specific operational parameters, in this case the
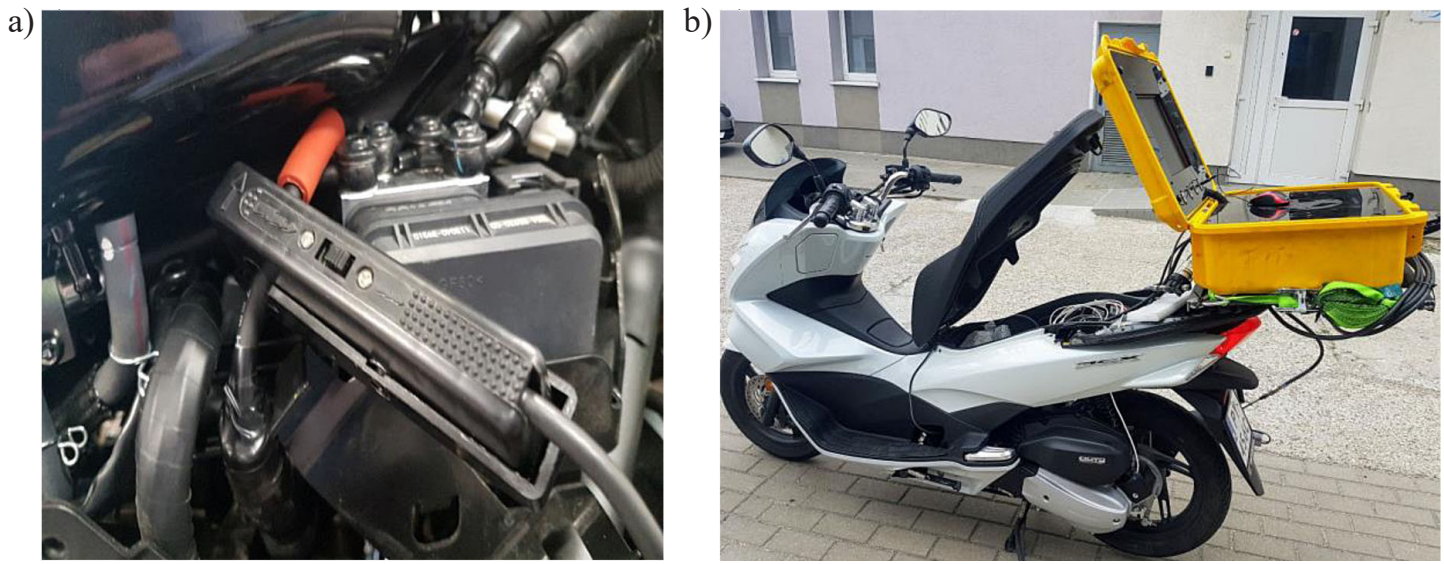

Figure 3. a) engine rpm sensor, b) test vehicle and the measuring equipment
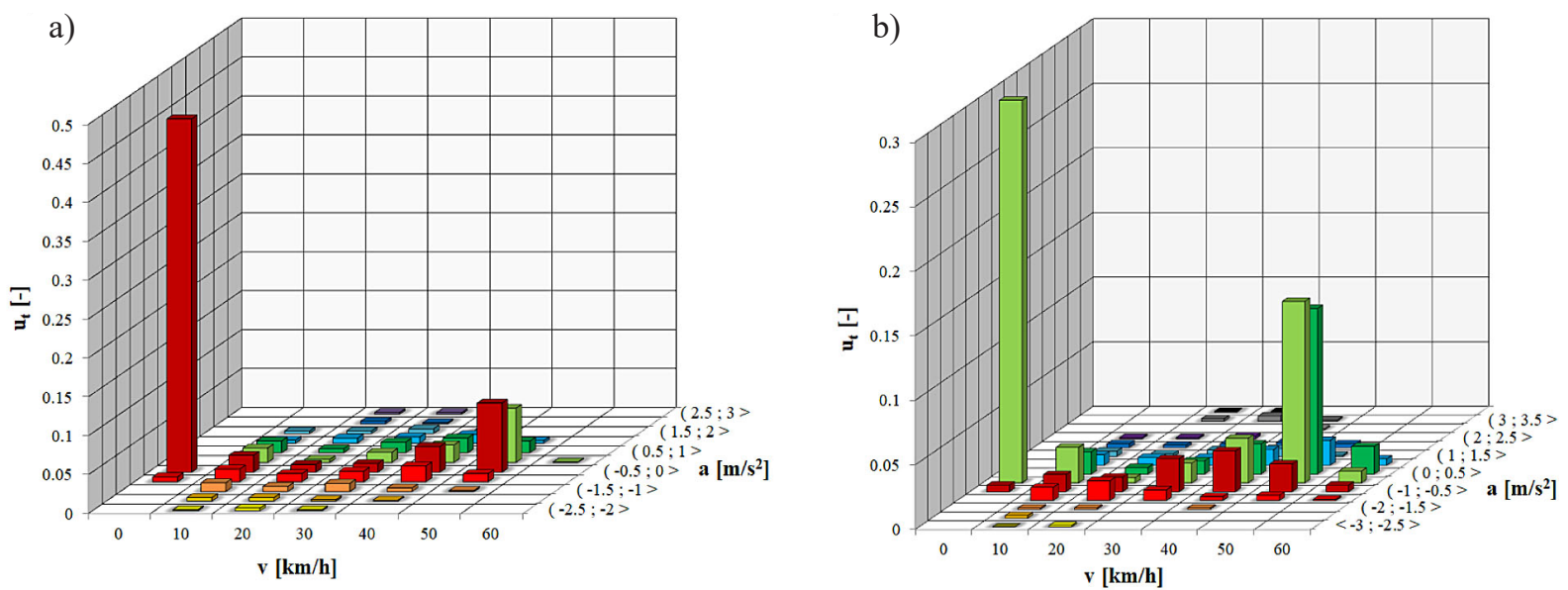

Figure 4. Time density characteristics of a two-wheeled vehicle:

a) in the test without using bus lanes, b) in the test using bus lanes 

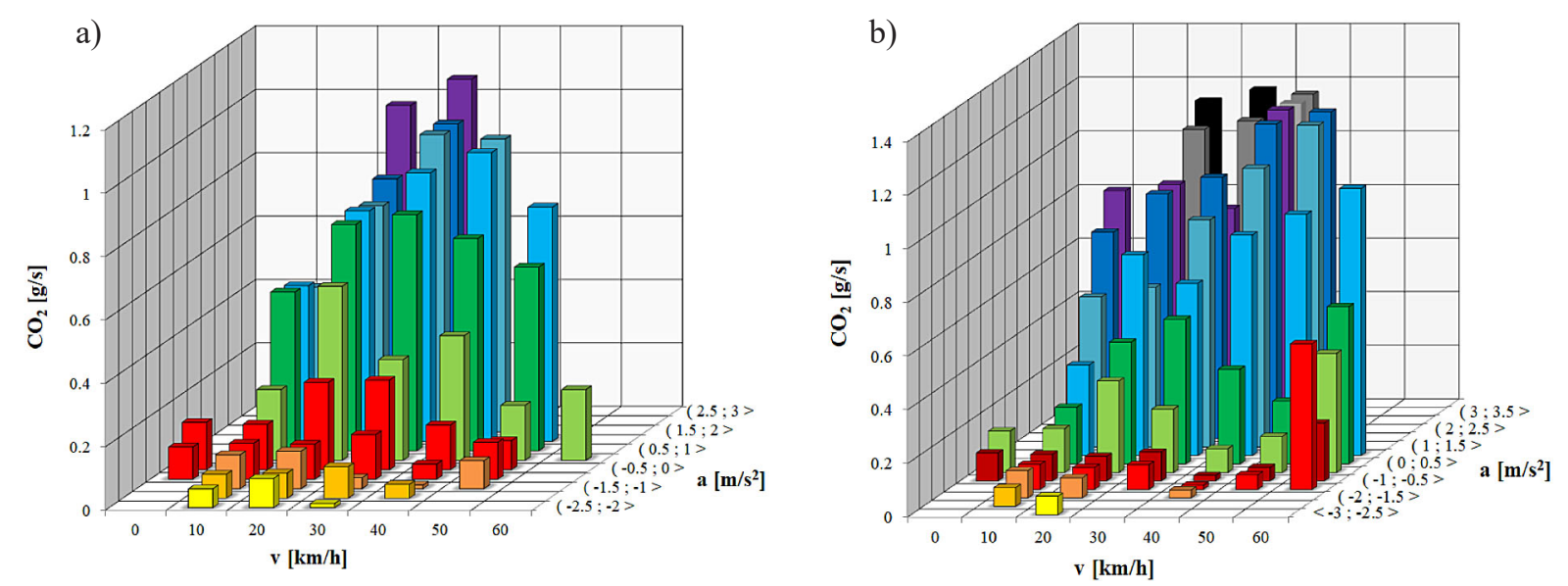

Figure 5. $\mathrm{CO}_{2}$ emission rate in the speed and acceleration intervals: a) in the test without using bus lanes, b) in the test using bus lanes

vehicle speed and its acceleration (in relation to the duration of the entire test). Moreover, a comparative analysis of the share of engine operating time for two different drive cycles was also carried out (standard route - without using bus lanes and another drive using the bus lanes as permitted). On the basis of the characteristics plotted it can be seen that in both cases, the vehicle was still most often in idle. However, the use of bus lanes reduced the share of this operating point by $15 \%$, which can be seen by the values of $45 \%$ and $30 \%$ for the drive cycles without bus lanes and with bus lanes, respectively (Fig. 4).

For the second drive, there were two other significant engine operating areas in the low accelerations range $\left(-0.5-0.15 \mathrm{~m} / \mathrm{s}^{2}\right)$ and high vehicle speeds (40-50 km/h), representing $27 \%$ of the total operating time of the engine, which confirms that avoiding the road congestion was possible to some extent and thus, a smoother ride of the test vehicle. The difference in the mean vehicle speed values of $15.6 \mathrm{~km} / \mathrm{h}$ and $24.1 \mathrm{~km} / \mathrm{h}$ also prove this.

\section{Emission indicators analysis}

Using the registered data on the engine operating parameters, it was possible to analyze their impact on the vehicle exhaust emissions. These assessments were carried out for both drive cycles with and without using bus lanes. The analysis extended to the toxic exhaust compounds limited by the Euro 4 emission norm by legislators (hydrocarbons, nitrogen oxides, carbon monoxide) as well as the emissions of harmful carbon dioxide.

The intensity of the $\mathrm{CO}_{2}$ emissions depends on both the vehicle speed and its accelerations, as well as its values were recorded in the entire speed range of the test vehicle (Fig. 5).

For the first drive without the use of bus lanes, the highest $\mathrm{CO}_{2}$ emission value of $1.05 \mathrm{~g} / \mathrm{s}$ was recorded at high accelerations in the interval (2.5-3 $\mathrm{m} / \mathrm{s}^{2}$ ) and average vehicle speeds in the interval range $(20-30 \mathrm{~km} / \mathrm{h})$. For the second drive cycles with bus lanes, the highest value was also recorded in the high accelerations interval $(1.5-2 \mathrm{~m} /$ $\mathrm{s}^{2}$ ) and speeds in the interval $(40-50 \mathrm{~km} / \mathrm{h})$, and it amounted to $1.22 \mathrm{~g} / \mathrm{s}$. The impact of bus lanes on the $\mathrm{CO}_{2}$ emissions is particularly notable in the final road emission values, which amounted to $50.67 \mathrm{~g} / \mathrm{km}$ and $37.08 \mathrm{~g} / \mathrm{km}$, respectively. The $26 \%$ difference between the values in favour of the second drive was undoubtedly influenced by the use of bus lanes and bypassing road congestion.

While analysing the $\mathrm{CO}$ emissions in the vehicle speed and acceleration intervals, it can be seen that it has a similar characteristic, as in the case of $\mathrm{CO}_{2}$ emissions, in the entire speed range of the tested scooter for both drive cycles (Fig. 6). On the basis of the characteristics, it can be seen that the local maxima in both cases fall into the interval of medium and high vehicle speeds in the ranges $(20-30 \mathrm{~km} / \mathrm{h})$ and $(30-40 \mathrm{~km} / \mathrm{h})$ and accelerations in the range $\left(2.5-3.5 \mathrm{~m} / \mathrm{s}^{2}\right)$. These values were $0.015 \mathrm{~g} / \mathrm{s}$ and $0.016 \mathrm{~g} / \mathrm{s}$ for the first drive without bus lanes and second one with bus lanes, respectively. High speed, and thus increased fuel doses supplied to the combustion chamber cause global and local oxygen deficiency, which is closely related to the formation of carbon oxides. In addition, their formation was influenced by the thermal state in the cylinder, which had the conditions conducive to $\mathrm{CO}_{2}$ dissociation. 

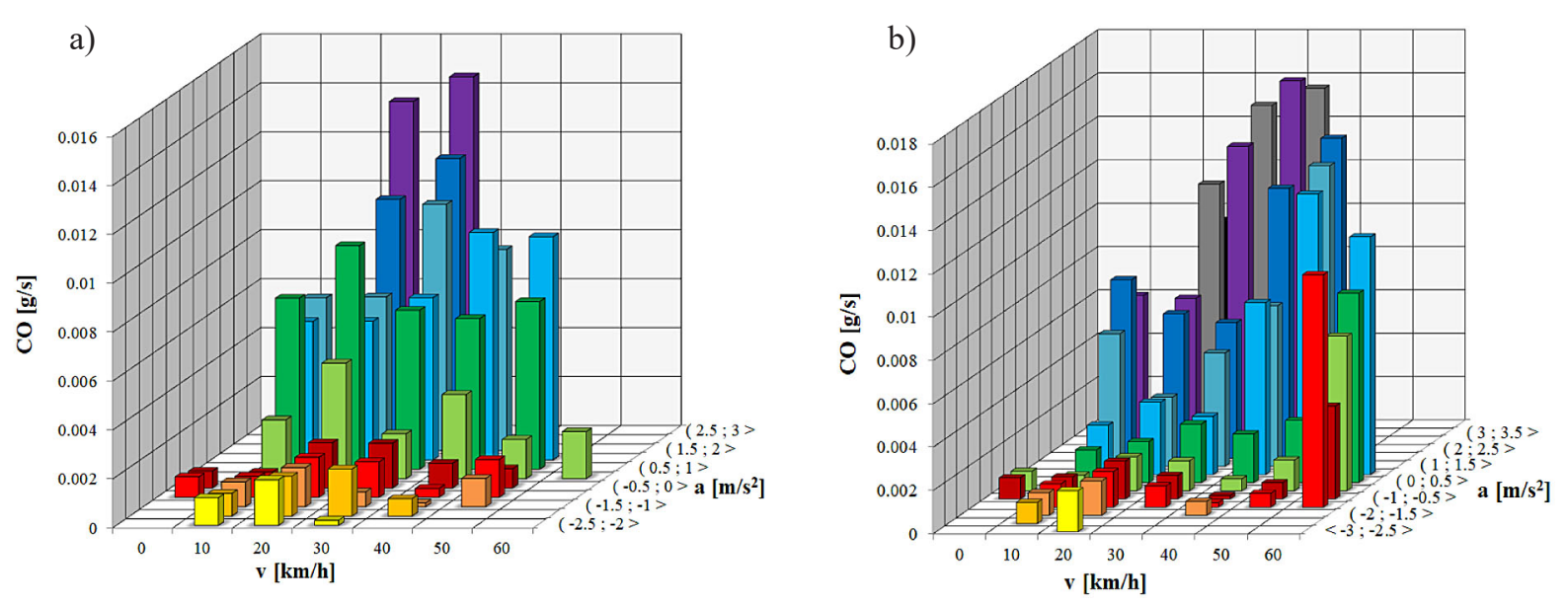

Figure 6. $\mathrm{CO}$ emission intensity in speed and acceleration intervals:

a) in the test without using bus lanes, b) in the test using bus lanes
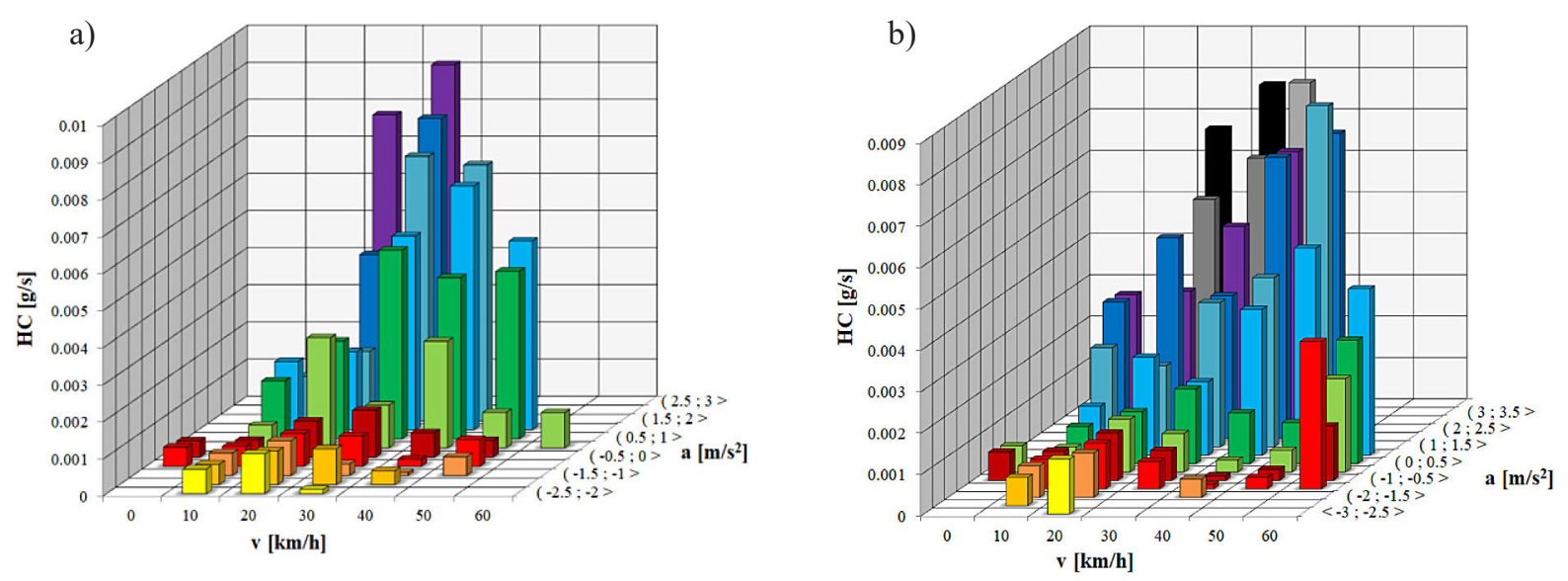

Figure 7. HC emission intensity in speed and acceleration intervals: a) in the test without using bus lanes, b) in the test using bus lanes

The average values of this relationship for both drives were $0.0018 \mathrm{~g} / \mathrm{s}$ and $0.0023 \mathrm{~g} / \mathrm{s}$, respectively. As in the case of $\mathrm{CO}_{2}$ emissions, the greatest impact of bus lanes on the $\mathrm{CO}$ emissions should be particularly visible in the final results of road emissions. The values of $0.41 \mathrm{~g} / \mathrm{km}$ and $0.35 \mathrm{~g} / \mathrm{km}$ were obtained for the first and second drives, respectively; the resulting difference between the tests was a $15 \%$ reduction in emission values for the second drive.

The characteristics of the hydrocarbon emission intensity as a function of vehicle speed and acceleration (Fig. 7) showed that the highest hydrocarbon emission values were in the intervals of medium and high accelerations and high vehicle speeds.

The highest value $(0.009 \mathrm{~g} / \mathrm{s})$ for the first test drive was recorded for the operating parameters in the intervals $\left(2.5-3 \mathrm{~m} / \mathrm{s}^{2}\right)$ and $(20-30 \mathrm{~km} / \mathrm{h})$. In turn, the highest value, $0.008 \mathrm{~g} / \mathrm{s}$, for the drive using bus lanes was observed in the intervals $\left(1-1.5 \mathrm{~m} / \mathrm{s}^{2}\right)$ and $(40-50 \mathrm{~km} / \mathrm{h})$. At high vehicle speeds, the injected fuel dose did not mix thoroughly and incomplete combustion occurred, which resulted in the increased production of hydrocarbons. The average value obtained in both tests was $0.0011 \mathrm{~g} / \mathrm{s}$. The final results of the hydrocarbon road emissions showed a $32 \%$ difference in favour of the second drive, and these values were $0.245 \mathrm{~g} / \mathrm{s}$ and $0.167 \mathrm{~g} / \mathrm{s}$, respectively.

The last toxic exhaust component analysed in the vehicle speed and acceleration intervals was $\mathrm{NO}_{x}$ (Fig. 8). As was the case with other compounds, the $\mathrm{NO}_{\mathrm{x}}$ emission depends on both of these operating parameters (Fig. 8). The highest values were observed in the intervals of high vehicle acceleration. The maximum value for the first drive was recorded for vehicle speed in the range $(20-30 \mathrm{~km} / \mathrm{h})$ and acceleration in the range $\left(2.5-3 \mathrm{~m} / \mathrm{s}^{2}\right)$, which reached $0.0012 \mathrm{~g} / \mathrm{s}$. During 

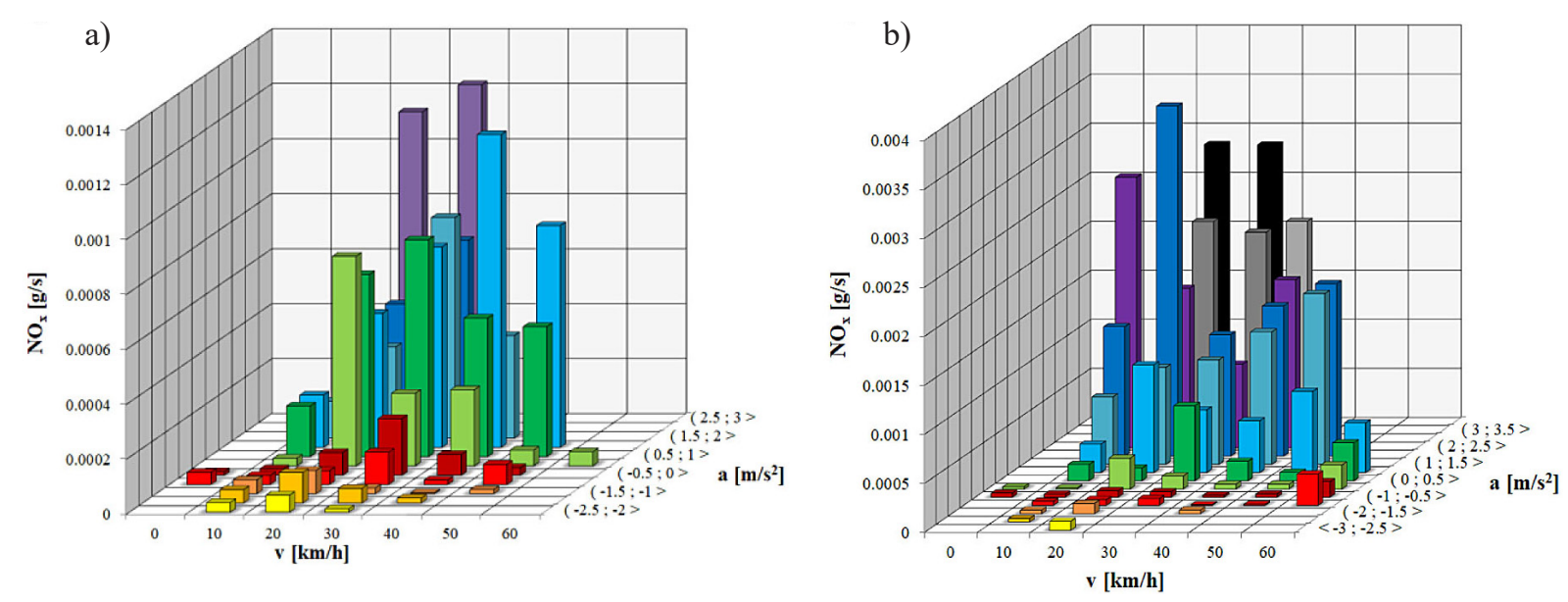

Figure 8. $\mathrm{NO}_{\mathrm{x}}$ emission intensity in speed and acceleration intervals:

a) in the test without using bus lanes, b) in the test using bus lanes

the second drive cycle, the highest value $(0.0036$ $\mathrm{g} / \mathrm{s}$ ) was recorded for the test vehicle speed in the range $(10-20 \mathrm{~km} / \mathrm{h})$ and acceleration interval $\left(1.5-2 \mathrm{~m} / \mathrm{s}^{2}\right)$. High vehicle acceleration value generates a higher temperature in the cylinder, which directly promotes the formation of nitrogen oxides. The greater instantaneous local maximum for the second drive was due to the road conditions and the possibility of the vehicle moving at a higher speed (bypassing road congestion); however, the final results of this drive's emission values show a positive ecological impact of the second drive. The difference was $4 \%$, and the calculated values were $0.026 \mathrm{~g} / \mathrm{s}$ and $0.027 \mathrm{~g} / \mathrm{s}$ for the test without using bus lanes and with using bus lanes, respectively.

In addition, the direct cost of congestion, i.e. the lost time, was 9 minutes, as the duration of the first drive was just over 25 minutes, while the second one took only 16 minutes. Comparing both travel time values to each other indicates a congestion level of 1.56. This value indicates how many times the travel time has been extended in the case of a drive in which the driver did not use the bus lanes at all. The indicated time to cover the test route, under the conditions without road congestion, by GoogleMaps was 12 minutes (optimal time), in this case the level of congestion was therefore 2.08 .

\section{CONCLUSIONS}

Road traffic is a common phenomenon in cities, and all urban road users suffer its negative effects. It causes significant costs, from lost time and increased wear of vehicles to atmospheric pollution, and its level is systematically increasing. Therefore, the authorities of most cities entitle the drivers who drive two-wheeled vehicles to use the municipal bus lanes. This solution was also allowed by the Poznan agglomeration in an effort to reduce the road congestion. The tests carried out on a motorcycle under real operating conditions have shown the positive effect of bus lanes on the level of exhaust emissions, reducing $\mathrm{CO}_{2}$ by $27 \%$, $\mathrm{HC}$ by $32 \%$ and $\mathrm{CO}$ by $15 \%$. In addition, the travel time was shorter by 9 minutes despite a short overall distance of $6.6 \mathrm{~km}$. The cost incurred due to the lost time as a result of extended travel times is a key category of direct traffic costs that burden all users of transport infrastructure.

The tests were carried out using the latest mobile measuring equipment, the mass and dimensions of which allow it to perform tests under real operating conditions even on smaller two-wheeled vehicles. The measurements of this type were difficult, if not impossible, to carry out using the equipment available up until nowadays, which is dedicated primarily to motor vehicles. New research capabilities allow for a wide range of measurements related to the exhaust emissions and operating conditions of mopeds and smaller motorcycles under real operating conditions. Only such studies can provide complete and reliable information on the exhaust emissions of vehicles. In many previous works by the authors, it was shown that the existing expenditure of the legislators on the legal solutions regarding the control of the toxic exhaust emissions from two-wheeled vehicles was insufficient. They are now more liberal compared to the regulations for PC category vehicles. A confirmation of that is the comparison of the road 
emission values of a two-wheeled vehicle, obtained based on the tests under real operating conditions, with limit the values stated in the legal norms. Therefore, the main direction of further efforts of the local and municipal authorities of all highly developed countries should be the gradual lowering of the toxic exhaust emission limit values from two-wheeled vehicles. To this end, the development of an RDE methodology dedicated specifically to the vehicles of this category, in particular for mopeds, should be prioritized. The subject of this article is a smaller part of the mopeds and motorbikes tests planned to be carried out under real operating conditions, and the whole set of obtained results will be used by the authors to develop the RDE methodology for the vehicles of this category.

\section{REFERENCES}

1. Bajerlein M., Rymaniak L., Swiatek P., Ziolkowski A., Daszkiewicz P., Dobrzynski M., 2014. Modification of a Hybrid City Bus Powertrain in the Aspect of Lower Fuel Consumption and Exhaust Emissions. Applied Mechanics and Materials 518, 108-113.

2. Ciesielski M., 1986. Koszty kongestii transportowej w miastach. Wydawnictwo Akademii Ekonomicznej w Poznaniu.

3. European Commission, 2011. White Paper: Roadmap to a Single European Transport Area-Towards a competitive and resource efficient transport system.
4. Igliński H. 2009. Ograniczanie poziomu kongestii transportowej a zrównoważony rozwój miast. Ph.D. Thesis, Poznan University of Economics and Buisness.

5. Kaminska M., Rymaniak L., Daszkiewicz P., Lijewski P., 2019. Test guidelines for evaluation real driving emission two-way vehicles. MATEC Web of Conferences 294.

6. Lijewski P., Szymlet N., Rymaniak L., Sokolnicka B., Domowicz A., 2019. The impact of operating conditions on exhaust emissions from a twowheeled urban vehicle 100.

7. Rymaniak Ł., Lijewski P., Kaminska M., Fuc P., Kurc B., Siedlecki M., Jagielski A., Kalocinski T., 2020. The role of real power output from farm tractor engines in determining their environmental performance in actual operating conditions. Computers and Electronics in Agriculture 173.

8. Rymaniak L., Ziolkowski A., Gallas D., 2017. Particle number and particulate mass emissions of heavy duty vehicles in real operating conditions. MATEC Web of Conferences 118.

9. Strzemkowski J., Merkisz-Guranowska A., Andrzejewski M., Stawecka H., Kaminska M., Far M., 2019. Innovative concept of loading bimodal trailers with the organization of a loading terminal. MATEC Web of Conferences 294.

10. Winston C., Shirley C., 2004. The impact of congestion on Shippers Inventory Costs. Final Report to Federal Highway Administration.

11. www.globalmrv.com

12. www.gpsvisualizer.com

13. www.ztm.poznan.pl 